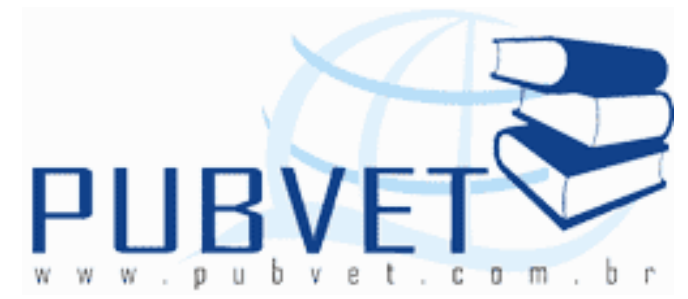

PUBVET, Publicações em Medicina Veterinária e Zootecnia.

Disponível em: <https://doi.org/10.31533/pubvet.v02n10a402>.

\title{
Etiologia, fisiopatologia e clínica da ceratoconjuntivite infecciosa bovina
}

Henrique Trevizoli Ferraz ${ }^{1}$, Ricardo Martins Morini², Marco Antônio de Oliveira Viu $^{1}$, Dyomar Toledo Lopes ${ }^{3}$, Janine de Freitas Alves ${ }^{2}$

${ }^{1}$ Professor do Curso de Medicina Veterinária - UFG/Jataí.

${ }^{2}$ Aluno(a) de Graduação em Medicina Veterinária - UFG/Jataí.

${ }^{3}$ Doutorando em Ciência Animal - EV/UFG.

\section{RESUMO}

A ceratoconjuntivite infecciosa bovina apresenta alta taxa de morbidade, principalmente nas épocas mais quentes do ano, causando perdas na produção de leite e carne, além dos prejuízos diretos devido ao custo e manejo dos tratamentos. O objetivo desta revisão de literatura foi abordar a etiologia, fisiopatologia, aspectos clínico-epidemiológicos e tratamento desta enfermidade.

PALAVRAS-CHAVE: conjuntivite, Moraxella bovis, Musca domestica, oxitetraciclina 


\title{
Etiology, physiopathology and clinic of bovine infectious keratoconjunctivitis
}

\begin{abstract}
Bovine infectious keratoconjunctivitis presents high rate of morbidity, particularly during the hottest of the year, causing losses in the production of milk and meat, in addition to the direct losses due to the cost of treatment and management. The purpose of this literature review was addressing the etiology, physiopathology, clinical and epidemiological aspects and treatment of this disease.
\end{abstract}

KEYWORDS: conjunctivitis, Moraxella bovis, Musca domestica, oxitetraciclin

\section{INTRODUÇÃO}

A ceratoconjuntivite infecciosa bovina (CIB) é uma doença que acomete bovinos, tem distribuição mundial e tem sido diagnosticada em vários estados brasileiros. É caracterizada por conjuntivite, lacrimejamento e ceratite (RIET-CORREA et al., 2001).

O impacto econômico causado pela doença é grande devido à perda da visão, que leva à redução do peso e da produção, gerando custos com tratamento e manejo. O prejuízo causado pela CIB nos países do MERCOSUL levou a considerá-la uma das oito doenças priorizadas para estudos através do PROCISUR (Programa de Desenvolvimento Científico do MERCOSUL) (CONCEIÇÃO \& TURNES, 2003).

Métodos de manejo e instalações adequados, associados à sanidade do rebanho e à utilização de um programa de vacinação são medidas que visam controlar e prevenir a doença, fazendo com que os gastos com tratamento e as perdas econômicas diminuam, tornando mais rentável a atividade. 
Ferraz, H.T., Morini, R.M., Viu, M.A.O. et al. Etiologia, fisiopatologia e clínica da ceratoconjuntivite infecciosa bovina. PUBVET, Londrina, V. 2, N. 41, Art\#402, Out4, 2008.

\section{ETIOLOGIA}

A CIB é causada pela Moraxella bovis, bactéria que faz parte da microbiota ocular de animais saudáveis e doentes, apresentando variedades fenotípicas e genotípicas, o que possibilita a diferenciação de cepas patogênicas (RIET-CORREA et al., 2001).

A $M$. bovis pertence atualmente à família Moraxellacea, sendo o gênero Moraxella constituído por 14 espécies. É uma bactéria Gram negativa, aeróbia, imóvel, oxidase positiva, variável para colagenase, que não fermenta carboidratos nem produz nitrato ou esporula. O pleomorfismo é uma característica da espécie, variando de cocos a cocobacilos e bacilos (CONCEIÇÃO \& TURNES, 2003). As $\beta$-hemolisinas, leucotoxinas, fímbrias e proteases são os fatores de virulência (RADOSTITS et al., 2002)

Segundo RIET-CORRREA et al. (2001), experimentos demonstraram que as fímbrias eram o fator de virulência primário, uma vez que cepas cujas fímbrias foram desnaturadas por tratamento químico perderam sua patogenicidade, autoaglutinabilidade e a propriedade de aglutinar hemácias.

Existem dois tipos de fímbrias, I e Q. A adesão da bactéria mediada pela fímbria $Q$ à córnea e o estabelecimento da infecção impedem a remoção do microorganismo pelo efeito do fluxo contínuo das secreções oculares e ação mecânica da pálpebra (RADOSTITS et al., 2002).

De acordo com CONCEIÇÃO \& TURNES (2003), cepas não hemolíticas são freqüentemente isoladas de bovinos e geralmente não estão associadas à doença clínica. Estudos recentes indicam que a $\beta$-hemolisina produz poros na membrana citoplasmática das células alvo (leucócitos, hemácias e células epiteliais), provocando efluxo de potássio e conseqüente lise.

A $M$. bovis é carreada tanto na conjuntiva como nas narinas dos bovinos. A persistência da doença de um ano para o outro se da por meio de animais infectados, que podem atuar como portadores por mais de um ano (RADOSTITS et al., 2002). 
A CIB ocorre principalmente nas épocas quentes, quando a população de mosca da face (Musca atumnalis), mosca da face asiática (Musca bezzii) e a mosca doméstica (Musca domestica) estão aumentadas, servindo estas de vetores mecânicos (CONCEIÇÃO \& TURNES, 2003). Além disso, a radiação solar, poeira, ventos, pastagens e outros insetos têm efeito multiplicador da patologia (RADOSTITS et al., 2002).

É uma doença altamente contagiosa podendo ser transmitida, de acordo com CONCEIÇÃO \& TURNES (2003), por contato direto, descarga nasal, ocular e principalmente por vetores mecânicos, sendo que a M. bovis pode sobreviver por até 72 horas nas patas das moscas que servem como vetores.

\section{FISIOPATOLOGIA}

A manifestação da doença inicia-se quando a $M$. bovis patogênica, que faz parte da microbiota ocular do portador ou é transmitida por vetores, sintetiza fímbrias de aderência. As fímbrias reconhecem receptores específicos presentes na conjuntiva, conduto lacrimal (fímbrias tipo a) e na córnea (fímbrias tipo $\beta$ ), fixando-se nas células (RIET-CORREA et al., 2001).

As exotoxinas com atividade enzimática produzidas pela $M$. bovis provocam lesões na superfície córnea, permitindo a invasão das bactérias e causando desorganização das fibras de colágeno (RIET-CORREA et al., 2001).

Segundo SMITH (1993), diversos fatores favorecem o acesso das bactérias ao estroma corneano. Foi demonstrado que a luz ultravioleta é capaz de lesionar o epitélio corneano, favorecendo o ingresso da Moraxella no estroma, sendo este um fator importante no aumento da incidência da doença no verão. Outros fatores como poeira, sementes e caules de vegetais ou outros irritantes mecânicos podem lesionar o epitélio corneano, favorecendo o ingresso da bactéria.

A luz ultravioleta facilita a infecção tanto por danificar as células epiteliais da córnea, como por ativar M. bovis não hemolítica na flora 
Ferraz, H.T., Morini, R.M., Viu, M.A.O. et al. Etiologia, fisiopatologia e clínica da ceratoconjuntivite infecciosa bovina. PUBVET, Londrina, V. 2, N. 41, Art\#402, Out4, 2008.

conjuntival de bovinos recuperados. As moscas, principais vetores, transportam cepas virulentas das secreções nasais e oculares dos animais infectados para os olhos dos não infectados (REBHUN, 2000).

De acordo com RADOSTITS et al. (2002), as secreções corneais estão presentes dentro de 12 horas após o início da infecção e uma reação inflamatória ocorre alguns dias após.

O processo inflamatório provoca edema de pálpebra e migração de células inflamatórias, com conseqüente opacidade de córnea. Outras bactérias patogênicas da microbiota ocular colonizam as lesões causadas pela M. bovis, contribuindo para o agravamento do quadro (RIET-CORREA et al., 2001).

A ruptura do colágeno estromal por hidrolases e proteases liberadas pelas bactérias e leucócitos polimorfonucleares e células da córnea, em último caso, pode causar uma formação de descematocele e perfuração da córnea. A cicatrização do local ulcerado ocorre devido à vascularização que atinge a área, com subseqüente remodelagem do colágeno corneano, produzindo a cicatriz corneana (SMITH, 1993).

\section{SINAIS CLÍNICOS}

O período de incubação pode ser de dois a três dias, chegando a até três semanas (CORRÊA \& CORRÊA, 1992). Os sinais clínicos são: congestão dos vasos corneais e edema da conjuntiva, acompanhados por lacrimejamento aquoso, blefaroespasmo, fotofobia, podendo, em alguns casos, ocorrer febre leve a moderada, diminuição do apetite e queda na produção (RADOSTITS et al., 2002).

Após dois a quatro dias do início da doença pode ser detectada ceratite. Observa-se área de opacidade na córnea que pode ser central ou pericentral (SMITH, 1993). Um ou ambos os olhos podem ser acometidos. O grau de ulceração nos estágios iniciais pode ser determinado pela infusão de 
Ferraz, H.T., Morini, R.M., Viu, M.A.O. et al. Etiologia, fisiopatologia e clínica da ceratoconjuntivite infecciosa bovina. PUBVET, Londrina, V. 2, N. 41, Art\#402, Out4, 2008.

solução de fluoresceína a $2 \%$ dentro do saco conjuntival, sendo que o corante ficará retido na área ulcerada (RADOSTITS et al., 2002).

Com a evolução da doença, a opacidade torna-se muito extensa e no pico da inflamação, cerca de seis dias após o aparecimento dos sinais clínicos, ela pode cobrir toda a córnea. A cor da opacidade pode variar do branco ao amarelo (RADOSTITS et al., 2002).

Nos casos em que a lesão inicial evolui, é freqüente que haja contaminação por outras bactérias da microbiota, podendo haver contaminação da câmara anterior do olho, que se mostra turva. É possível também observar a invasão da córnea por vasos neoformados a partir do sulco esclero-corneal, o que consolida a perda da transparência (RIET-CORREA et al., 2001).

As úlceras se tornam mais profundas ao longo dos dias. O corrimento ocular se torna mucopurulento. Uma vascularização ao redor do limbo começa a invadir a córnea depois de quatro a sete dias do aparecimento da úlcera, que terá aspecto amarelado em decorrência da necrose e infiltração de leucócitos adjacentes à lesão no estroma corneano. Os vasos sangüíneos corneanos atingem as margens da úlcera, e um tecido de granulação começa preencher o defeito. Em geral dentro de duas a três semanas após o surgimento da doença a córnea estará reepitelizada (SMITH, 1993).

Nos casos mais graves a córnea fica cônica, ocorre vascularização da mesma e a ulceração no ápice do edema leva à supuração da córnea com pus amarelo claro circundado por uma área de eritema. Pode haver rompimento resultando em cegueira completa (RADOSTITS et al., 2002).

Em alguns casos podem haver lesões clínicas mínimas e cura espontânea. A gravidade da doença pode variar também entre os surtos (RADOSTITS et al., 2002). 
Ferraz, H.T., Morini, R.M., Viu, M.A.O. et al. Etiologia, fisiopatologia e clínica da ceratoconjuntivite infecciosa bovina. PUBVET, Londrina, V. 2, N. 41, Art\#402, Out4, 2008.

\section{DIAGNÓSTICO}

O diagnóstico da CIB é baseado nos estudo epizootiológico e nas manifestações clínicas.

Mesmo o diagnóstico sendo baseado nos sinais clínicos, as secreções dos olhos afetados podem ser cultivadas para possível isolamento da linhagem de M. bovis e teste de sensibilidade aos antibióticos (SMITH, 1993). O material a ser coletado é o líquido conjuntival de animais em fase inicial da doença, antes do aparecimento das lesões na córnea. A caracterização é feita de acordo com as características do agente: bacilo ou cocobacilo; isolados ou em pares; Gram negativos; reação de oxidase positiva; autoaglutinação em suspensão em solução salina a $0,85 \%$; produção de gelatinase; oxidação de glucose negativa; e redução de nitrato negativa (RIET-CORREA et al., 2001). Segundo RADOSTITS et al. (2002), os exames de necropsia não são necessários na maioria das vezes.

\section{TRATAMENTO}

Para impedir a evolução da doença e evitar lesões irreparáveis na córnea é necessário iniciar o tratamento imediatamente após o diagnóstico. Antibióticoterapia pode ser feita por via parenteral, aplicações subconjuntivais ou de forma tópica no saco conjuntival (RIET-CORREA et al., 2001).

Os antibióticos recomendados por SMITH (1993) para instilação tópica subconjuntival são ampicilina, bacitracina, neomicina, oxitetraciclina, penicilina, canamicina e gentamicina.

Em casos onde a terapia tópica não possa ser facilmente aplicada, as injeções subconjuntivais podem ser uma alternativa, embora estas mantenham elevada concentração corneana. São necessárias duas a três aplicações por dia, para que a concentração seja mantida. Isso pode ser mais inconveniente que as repetidas aplicações tópicas de antibióticos (SMITH, 1993). 
Devido à intensidade de trabalho gerado pelos tratamentos locais, tanto para os clientes como para os médicos veterinários, estes se tornam cada vez menos atraente (SMITH, 1993). Com isso tem-se investigado o cloridrato de oxitetraciclina de longa ação, por via intramuscular, e obtido resultado satisfatório contra M. bovis, pela sua distribuição seletiva para as glândulas lacrimais e epitélio conjuntival. Deve-se administrar cloridrato de oxitetraciclina longa ação por via intramuscular na dose de $20 \mathrm{mg} / \mathrm{kg}$ de peso vivo e repetir a dosagem 72 horas depois (REBHUN, 2000).

Segundo REBHUN (2000), a oxitetraciclina não deve ser utilizada por via subconjuntival por ser extremamente irritante para o olho quando aplicada por esta via. Os medicamentos antiinflamatórios esteroidais não devem ser usados durante a fase ulcerativa da doença, podendo interferir nos estágios de cicatrização, na redução da vascularização e granulação. Embora os corticosteróides possam reduzir a inflamação, tais agentes potenciam a perfuração da córnea e aumenta a taxa de eliminação de $M$. bovis nas secreções oculares (SMITH, 1993).

Quando ocorre úlcera de córnea o uso de anestésicos oftálmicos tópicos, associados à atropina, pode ser indicado para minimizar o espasmo ciliar e a dor. Em casos graves, os animais devem ser colocados em alojamento escuro e livre da luz solar direta ou a terceira pálpebra pode ser suturada temporariamente sobre o globo ocular para promover a cura (RADOSTITS et al., 2002).

Os olhos que sofrem perfuração profunda ou desenvolvem ceratocomo severo com endoftalmia ou panoftalmia, devem ser enucleados para evitar a dor, irritação por parte das moscas, descargas e quedas contínuas na produção e no crescimento (REBHUN, 2000). 
Ferraz, H.T., Morini, R.M., Viu, M.A.O. et al. Etiologia, fisiopatologia e clínica da ceratoconjuntivite infecciosa bovina. PUBVET, Londrina, V. 2, N. 41, Art\#402, Out4, 2008.

\section{PREVENÇÃo E CONTROLE}

Atualmente são comercializadas algumas vacinas com bacterinas contra M. bovis e estão sendo usadas em rebanhos onde a CIB ocorre com freqüência. As vacinas podem não conferir $100 \%$ de imunidade, mas reduzem significativamente a incidência da doença, os gastos com mão-de-obra, drogas e encargos com veterinários. O controle de moscas para reduzir os vetores é indicado. Existem brincos com inseticida, sacos de inseticida em pó e produtos químicos orais que são eliminados nas fezes e controlam larvas de moscas, dentre outras medidas com intenção de diminuir os vetores (REBHUN, 2000).

$\mathrm{Na}$ década de 80 foi testada uma vacina feita com cepas que expressavam fímbrias e esta protegeu cerca de $83,4 \%$ dos animais agredidos. Vacinas contendo este tipo de antígeno estão sendo utilizadas atualmente (RIET-CORREA et al., 2001).

Outras medidas de controle são: isolamento dos animais afetados; ceifagem das pastagens excessivamente crescidas, para reduzir os traumatismos oculares; reduzir poeira e pólen do ambiente dos animais e oferecer sombra e espaço para os animais confinados. Durante o tratamento, os seres humanos devem lavar as mãos ou usar luvas descartáveis de um animal para outro, para não atuarem como fômites (SMITH, 1993).

Os bovinos acometidos pela doença não devem ser misturados com os que não foram acometidos até que acabe a estação das moscas (RADOSTITS et al., 2002).

\section{CONSIDERAÇÕES FINAIS}

A CIB é uma doença bastante preocupante do ponto de vista econômico pois, apesar de sua mortalidade ser muito baixa, a morbidade é alta. Com isso, gastos com mão-de-obra, medicamentos e assistência veterinária diminuem o lucro na produção de carne e de leite. 
Ferraz, H.T., Morini, R.M., Viu, M.A.O. et al. Etiologia, fisiopatologia e clínica da ceratoconjuntivite infecciosa bovina. PUBVET, Londrina, V. 2, N. 41, Art\#402, Out4, 2008.

Por se tratar de uma doença que possui vacina para proteção do rebanho, a vacinação e os cuidados com limpeza para diminuição da proliferação dos vetores são boas práticas de profilaxia, mais viáveis que o tratamento, ainda que este seja relativamente simples.

\section{REFERÊNCIAS}

1. CONCEIÇÃO, F. R.; TURNES, C. G. Moraxella bovis: Influência das Características Genotípicas e Fenotípicas co Controle da CIB. Santa Maria - RS: Ciência Rural, 2003. Vol. 33, $\mathrm{n}^{\circ}$ 004, pp. 779-788. Disponível em: http://www.scielo.br/scielo.php?script=sci arttext\&pid=S0103-84782003000400033. Acesso em: 17/04/2008.

2. CORRÊA, W. M.; CORRÊA, C. N. M.; Enfermidades Infecciosas dos Mamíferos Domésticos. Rio de Janeiro - RJ: Medsi, 1992. 2.ed. 843p.

3. RADOSTITS, O. M.; GAY, C. C.; BLOOD, D.C.; et. al. Clínica Veterinária. Rio de Janeiro RJ: Guanabara Koogan S.A., 2002. 9.ed. 1773p.

4. REBHUN, W. C. Doenças do Gado Leiteiro. São Paulo - SP: Roca Ltda, 2000. 642p.

5. SMITH, B. P. Tratado de Medicina Interna de Grandes Animais. São Paulo - SP: Manole, 1993. vol.2. 1783p. 